\title{
Understand Nature, Stay Healthy: Health Tips from Ayurveda
}

\section{Goswami DK*}

Government Ayurvedic College, India

*Corresponding author: Dr. Dilip Kr. Goswami MD (AYURVEDA), Ph.D, Associate Professor, Agada Tantra and Vidhi Ayurveda (Toxicology and Forensic Medicine), Government Ayurvedic College , Guwahati, Assam, India, Tel: 9864351115; E-mail: drdilipgoswami37@gmail.com

\author{
Editorial \\ Volume 5 Issue 1
}

Received Date: January 08, 2021

Published Date: February 08, 2021

DOI: $10.23880 /$ jonam-16000298

\section{Editorial}

Each and every individual is cautious about his/her health. Disease always waits for opportunity to attack the living organisms. In other sense it can be said that, every individual has succeptibility to disease. Anyone can get diseased at any moment if the opportunistic disease gets scope. It is well accepted that, almost all diseases are caused due to (1) imbalance in the anatomical/physiological integrity of the organ/organs or system/systems and (2) invasion of some organisms from the surroundings. Interestingly, when the formation and integrity of the organs/systems is studied it becomes clear that, they become diseased due to malpractice in food and behavior whereas infection occurs due to low resistance of the individual which is again related with faulty diet and behavior.

Ayurveda is a system of health science that developed from the observation and concept on the nature. The concept of development of the human body is directly correlated with the nature by the Ayurvedic scholars. Like the maintenance of the nature's integrity by the 3 components (1) the Sun (Suryya), (2) the Moon (Soma- Chandra) and (3) the Air (Anila-Vayu) human body is also formed and keeping functioned by three factors (1)a unit that is responsible for production of heat, regulation of digestion, producing colour , conversion of the body elements (Dhatu) from one form to another etc. All these are like the functions of the Sun in the nature (Pitta). (2) Another unit which controls and maintains the coolness of the body, provides stability, prevents the dryness of the skin and other organs etc. It's functions are closely similar to the functions of the Moon in the nature (Kafa). (3) The third unit is responsible for initiation and maintenance of all the visible and invisible movements of the body elements like the hands, feet, head, respiration, walking, running, lymphatic circulation, blood circulation etc. Its functions are closely resembled with the functions of the air in the nature (Vata/Vayu). With this concept the
Ayurvedic scholars describe the human as well as the body of other living organisms correlating with the nature.

According to the concept of the Ayurvedic scholars all the substances available in the nature are formed with combination of 5 natural elements (Pancha mahabhutaPrithvi-eart-soil, Ap/Jal-water, Teja-fire, Marut-air and Vyom/Akasah-vaccum) in different proportions. According to the properties of the dominant natural element the substance reflects its property.

Basing upon the concept on the 5 natural elements, 3 body elements and the substances available in nature, in brief, the following remarks can be mentioned to reflect the relation between the nature and the human body.

1. Human body is composed with three basic elements which are formed with the contribution of the 5 natural elements in different proportions.

2. Integrity and functioning of the nature is maintained and regulated by the functions of the three governing factors-the Sun, the Moon and the Air.

3. Since the governing force of the human body is natural hence there is close relation between the change in the nature and change in the human body. To make it clear it can be said that, when the influence of the Sun on the nature increases (the environmental temperature increases) then the influence of "Pitta", which is responsible for regulation of heat, digestion etc, also increases. Hence, during this period there is need of opting the measures to bring down the effects of it.

4. All plants, minerals, food, drink etc, upon which the human society is dependent in various way, are also being regulated by the nature. Hence they also follow the commands of the nature in relation to their properties.

5. "Nature is the best healer" is the well accepted saying which is self explanatory in connection with the relation 


\section{Journal of Natural \& Ayurvedic Medicine}

between the nature and the human society.

6. Study of the Ayurvedic classics reflects that, an individual, if become successful in following the rules and regulations in relation to diet and behavior observing the character appearing in the nature, specially in relation to the Sun, Moon and Air then there will be no imbalance in the structural and functional integrity of the anatomical and physiological components and no disease will be able to disturb in his/her peace and harmony. Ayurvedic classics are rich with the tips of understanding the nature for the benefit of the individuals. Seasonal changes, probable diseases, preventive measures, daily regimens, night regimens are the important and beneficial contents of the ancient Ayurvedic classics.

It is hoped that, analytical study, evaluation, experiment and education of the ayurvedic classics in relation to the tips of understanding the nature and utilization of the knowledge for attainment of health will definitely give benefit to the human society

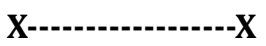

